\title{
New insights into the pathophysiology of mild chronic obstructive pulmonary disease
}

\author{
Jordan A Guenette BHK MSc PhD
}

JA Guenette. New insights into the pathophysiology of mild chronic obstructive pulmonary disease. Can Respir J 2014;21(1):25-27.

The classification of mild chronic obstructive pulmonary disease (COPD) requires a postbronchodilator forced expiratory volume in $1 \mathrm{~s}\left(\mathrm{FEV}_{1}\right)$ to forced vital capacity ratio $<0.7$ and an $\mathrm{FEV}_{1} \geq 80 \%$ predicted. Given their relatively well-preserved spirometry, some have argued that respiratory symptoms in patients with mild COPD are unlikely to be related to pulmonary function abnormalities and that early detection of COPD is a 'waste of resources'. Despite this viewpoint, there is emerging clinical and physiological evidence of peripheral airway dysfunction, diminished quality of life and reduced physical activity levels, and increased mortality, hospitalizations, dyspnea and exercise intolerance in patients with mild COPD compared with healthy controls. The purpose of the present focused review was to summarize recent research regarding the pathophysiology and treatment of mild COPD.

Key Words: Dyspnea; Exercise; GOLD I

$\mathrm{C}$ hronic obstructive pulmonary disease (COPD) is a highly prevalent condition resulting in significant morbidity and mortality. Treatment and diagnosis of COPD has traditionally been focused on the more advanced stages of the disease. However, there is growing interest in early diagnosis and intervention because this may have beneficial effects on disease progression and various clinical outcomes. Despite this, patients with spirometrically defined mild COPD are rarely included in clinical trials and there remains considerable controversy surrounding the clinical relevance of this stage of COPD. Part of this controversy relates to the potential for misclassification and misdiagnosis when using a fixed forced expiratory volume in $1 \mathrm{~s}$ $\left(\mathrm{FEV}_{1}\right) /$ forced vital capacity ratio. The present focused review highlights new evidence that looks beyond spirometry to demonstrate the complex physiological abnormalities that exist in patients with mild COPD.

\section{PULMONARY FUNCTION ABNORMALITIES}

Routine spirometry does not accurately reflect the vast pathophysiological heterogeneity that exists in patients with mild COPD. A recent cross-sectional study examined the relationship between several pulmonary function parameters across all stages of COPD severity $(n=2265)$ (1). Patients with mild COPD had increased air trapping (residual volume $135 \%$ predicted), reduced mid-volume expiratory flows (39\% predicted) and increased specific airways resistance (250\% predicted). As a group, patients with mild COPD had lower values for carbon monoxide diffusing capacity (DLCO) compared with controls but were still within the normal range (89\% predicted). Nevertheless, there was considerable heterogeneity in DLCO values, with approximately $20 \%$ of mild COPD patients having DLCO $<70 \%$ predicted. These findings suggest that the surface area for gas exchange is abnormal in a subset of patients with relatively well-preserved spirometry. This finding extends previous work demonstrating important pulmonary gas exchange and vascular abnormalities in mild COPD (2). For example, Rodríguez-Roisin et al (2) examined resting pulmonary gas exchange and ventilation/perfusion (VA/Q) imbalance in 150 patients

\section{De nouveaux aperçus sur la physiopathologie de la maladie pulmonaire obstructive chronique bénigne}

Pour classer la maladie pulmonaire obstructive chronique (MPOC) bénigne, il faut coefficient de moins de 0,7 entre le volume expiratoire maximal par seconde (VEMS) postbronchodilateur et la capacité vitale forcée et une VEMS d'au moins 80 \% de la valeur prévue. Étant donné la préservation relativement satisfaisante de la spirométrie, certains prétendent que les symptômes respiratoires des patients ayant une MPOC bénigne sont peu susceptibles d'être causés par des anomalies de la fonction pulmonaire et que le dépistage précoce de la MPOC constitue un « gaspillage des ressources ». Malgré ce point de vue, des données cliniques et physiologiques émergentes démontrent une dysfonction des voies aériennes périphériques, une diminution de la qualité de vie et une réduction de la quantité d'activité physique ainsi qu'une augmentation de la mortalité, des hospitalisations, de la dyspnée et de l'intolérance à l'exercice chez les patients ayant une MPOC bénigne par rapport aux sujets témoins en bonne santé. La présente analyse ciblée visait à résumer les recherches récentes sur la physiopathologie et le traitement de la MPOC bénigne.

across all stages of COPD severity. They demonstrated that nearly all patients with mild COPD had an abnormally widened alveolar-toarterial oxygen pressure gradient at rest and an abnormal VA/Q. The authors concluded that VA/Q imbalance, primarily perfusion heterogeneity, is disproportionally abnormal relative to spirometric measures of airflow limitation in patients with mild COPD.

\section{SENSORY AND PHYSIOLOGICAL RESPONSES TO EXERCISE}

Exercise performance and dyspnea

The long-standing view that patients with mild COPD do not experience clinically relevant respiratory impairment has recently been challenged by several studies using cardiopulmonary exercise testing in patients with mild COPD (3-5). Ofir et al (3) reported that symptomatic patients with mild disease demonstrated diminished exercise performance and reduced peak oxygen consumption relative to controls. Importantly, these authors found that dyspnea intensity was consistently elevated for any given work rate and ventilation in the patients with mild disease. These differences occurred at relatively low work rates that mimic the metabolic requirements of basic daily activities (eg, stair walking). Interestingly, the effects of dyspnea in mild COPD appear to be even more pronounced in women (4), a finding that is consistent with patients in the more advanced stages of COPD.

\begin{abstract}
Ventilatory responses
Ventilatory requirements are consistently elevated for any given exercise intensity in patients with mild COPD relative to controls (3-5). Studies also consistently demonstrate greater ventilatory inefficiency during exercise as reflected by an increased ventilatory equivalent for carbon dioxide $\left(\mathrm{CO}_{2}\right)(3-5)$. This is likely due to an increased physiological dead space because of regional increases in VA/Q. The more rapid and shallow breathing pattern observed in mild COPD also contributes to increased dead-space ventilation. The partial pressure of end-tidal $\mathrm{CO}_{2}$ is also consistently lower at rest and during all exercise intensities in mild COPD relative to controls, indicating the presence
\end{abstract}

Department of Physical Therapy and Centre for Heart Lung Innovation, University of British Columbia, Vancouver, British Columbia Correspondence: Dr Jordan A Guenette, UBC Centre for Heart Lung Innovation, St Paul's Hospital, 166 - 1081 Burrard Street, Vancouver,

British Columbia V6Z 1Y6. Telephone 604-806-8346, fax 604-806-9274, e-mail jordan.guenette@hli.ubc.ca 
of chronic alveolar hyperventilation and potential - and as yet unidentified - alterations in the ventilatory control system.

\section{Tidal volume constraints}

Expiratory flow limitation is the pathophysiological hallmark of COPD, which often results in progressive increases in end-expiratory lung volume above its resting value during exertion (ie, dynamic hyperinflation). Recent evidence clearly demonstrates that dynamic hyperinflation and its associated adverse consequences occur in the vast majority of patients with mild COPD (3-7). The effects of such mechanical ventilatory constraints on dyspnea were recently explored in a study that compared the effects of ventilatory stimulation during exercise in patients with mild COPD and healthy controls (5). The addition of a $600 \mathrm{~mL}$ dead space to the breathing apparatus caused an appropriate increase in tidal volume $\left(\mathrm{V}_{\mathrm{T}}\right)$ and end-inspiratory lung volume (EILV) in the controls. This suggests that healthy individuals have an adequate volume reserve and are not ventilatory limited during normal exercising conditions. In contrast, the mild COPD group failed to increase EILV and had relatively minor increases in $V_{T}$ despite ventilatory stimulation. This inability to appropriately increase $\mathrm{V}_{\mathrm{T}}$ was associated with a greater increase in dyspnea intensity in the patients with mild COPD. The results of that study demonstrate that the respiratory system in mild disease reaches or approaches its physiological limits at lower work rates and ventilations relative to healthy individuals.

\section{Symptomatic versus asymptomatic mild COPD}

The majority of the aforementioned studies focused on symptomatic outpatients and the responses of these individuals may not reflect the responses of asymptomatic individuals with similar disease severity based on spirometry. A recent study evaluated the physiological determinants of dyspnea and exercise intolerance during a 6 min walk test in symptomatic and asymptomatic patients meeting spirometric criteria for mild COPD and control smokers with normal spirometry (8). Subjects were classified as symptomatic if they had a modified Medical Research Council dyspnea score $\geq 1$. The study demonstrated that smokers with normal spirometry have remarkably similar sensory and physiological responses to exercise compared with asymptomatic patients with mild COPD. In contrast, symptomatic patients with mild COPD experienced higher levels of dyspnea, greater ventilatory inefficiency, pulmonary gas exchange abnormalities, expiratory flow limitation, dynamic hyperinflation and diminished exercise capacity relative to the other groups. They also had more emphysema, lower airway luminal area and thigh muscle mass wasting detected using computed tomography. These results demonstrate the fundamental importance of assessing chronic activity-related dyspnea in the clinical setting, even in mild disease in which spirometry remains relatively well preserved.

\section{PHARMACOTHERAPY}

It has been difficult to make recommendations regarding the effective pharmacological management of mild COPD because these patients are rarely included in clinical trials. Based on the increased level of exertional dyspnea and the vast physiological abnormalities already described, it appears reasonable to speculate that pharmacotherapy may have beneficial effects in selected symptomatic patients with mild disease. Three recent exploratory studies examined the effects of pharmacotherapy in patients with mild COPD $(6,7,9)$. A randomized cross-over study demonstrated that single-dose inhalation of nebulized ipratropium bromide resulted in improved $\mathrm{FEV}_{1}$, resting hyperinflation and airway resistance in 16 patients with mild COPD (7). During cycle exercise, ipratropium bromide improved $V_{T}$ expansion and significantly reduced the work of breathing, pulmonary resistance and hyperinflation with modest (but inconsistent) improvements in dyspnea; however, the effects on endurance time were not statistically significant. Similarly, six weeks of treatment with fluticasone/salmeterol combination in 15 patients with mild-to-moderate COPD (10 mild; five moderate) resulted in improvements in airway function at rest and during cycle exercise but the effects on dyspnea and endurance time were highly variable and did not reach statistical significance (6). Finally, Gagnon et al (9) evaluated the effects of nebulized ipratropium bromide and salbutamol sulfate combination on walking performance in 37 patients with mild COPD. The authors also found beneficial effects on dynamic operating lung volumes and breathing patterns during exercise but this did not translate into improved walking endurance or dyspnea. Collectively, these studies suggest that pharmacotherapy has beneficial effects on airway function both at rest and during exercise. However, the effects on important clinical outcomes appear to be highly variable. At this time, a definitive recommendation regarding the pharmacological management of mild COPD cannot be made due to a lack of sufficiently powered clinical trials. As such, caregivers must use their best judgment based on clinical presentation when deciding on treatment options for individual patients with milder COPD.

\section{PULMONARY REHABILITATION}

There is emerging evidence that patients with mild COPD avoid physical activity (10). This has important clinical implications given the well-documented downward spiral associated with activity avoidance, deconditioning and dyspnea in more advanced COPD. It follows that promoting physical activity, similar to smoking cessation, should be a top priority in the management of patients with mild COPD. The efficacy of formal exercise training as part of pulmonary rehabilitation (PR) programs has not been fully established in patients with mild disease. A recent systematic review concluded that PR has beneficial effects on exercise capacity and quality of life in individuals with mild disease; however, there remains insufficient data to make definitive conclusions (11). It may be reasonable to predict that patients with mild COPD may actually derive greater physiological benefits from exercise training compared with their counterparts with more severe disease because they are not yet hindered by incapacitating dyspnea and can, therefore, exercise at higher intensities. However, this hypothesis remains speculative and untested. Future work is needed to evaluate the efficacy and cost effectiveness of formal PR programs for patients with mild COPD.

\section{CONCLUSION}

Spirometric measures of airflow limitation do not adequately reflect the complex pathophysiology of mild COPD. When the respiratory system is experimentally stressed with exercise, several respiratory abnormalities with attendant negative sensory consequences can be uncovered in this population. In fact, these physiological abnormalities often mimic the responses typically observed in more advanced stages of COPD. Exploratory studies suggest that pharmacotherapy has beneficial effects on airway physiology in patients with mild disease; however, the clinical relevance of these improvements remains to be determined in the absence of important changes in dyspnea and exercise tolerance. Appropriately powered clinical trials are clearly needed to evaluate the efficacy and safety profile of various pharmacological and nonpharmacological interventions for the management of patients with mild COPD.

FUNDING: JG was supported by a New Investigator Award from the Providence Health Care Research Institute and St Paul's Hospital Foundation.

DISCLOSURES: The author has no financial disclosures or conflicts of interest to declare. 


\section{REFERENCES}

1. Deesomchok A, Webb KA, Forkert L, et al. Lung hyperinflation and its reversibility in patients with airway obstruction of varying severity. COPD 2010;7:428-37.

2. Rodriguez-Roisin R, Drakulovic M, Rodriguez DA, et al. Ventilation-perfusion imbalance and chronic obstructive pulmonary disease staging severity. J Appl Physiol 2009;106:1902-8.

3. Ofir D, Laveneziana P, Webb KA, et al. Mechanisms of dyspnea during cycle exercise in symptomatic patients with GOLD stage I chronic obstructive pulmonary disease. Am J Respir Crit Care Med 2008;177:622-9.

4. Guenette JA, Jensen D, Webb KA, et al. Sex differences in exertional dyspnea in patients with mild COPD: Physiological mechanisms. Respir Physiol Neurobiol 2011;177:218-27.

5. Chin RC, Guenette JA, Cheng S, et al. Does the respiratory system limit exercise in mild chronic obstructive pulmonary disease? Am J Respir Crit Care Med 2013;187:1315-23.

6. Guenette JA, Webb KA, O'Donnell DE. Effect of fluticasone/ salmeterol combination on dyspnea and respiratory mechanics in mild-to-moderate COPD. Respir Med 2013;107:708-16.
7. O'Donnell DE, Laveneziana P, Ora J, et al. Evaluation of acute bronchodilator reversibility in patients with symptoms of GOLD stage I COPD. Thorax 2009;64:216-23.

8. Diaz AA, Morales A, Diaz JC, et al. CT and physiologic determinants of dyspnea and exercise capacity during the sixminute walk test in mild COPD. Respir Med 2013;107:570-9.

9. Gagnon P, Saey D, Provencher S, et al. Walking exercise response to bronchodilation in mild COPD: A randomized trial. Respir Med 2012;106:1695-705.

10. Van Remoortel H, Hornikx M, Demeyer H, et al. Daily physical activity in subjects with newly diagnosed COPD. Thorax 2013;68:962-3.

11. Jacome CI, Marques AS. Pulmonary rehabilitation for mild chronic obstructive pulmonary disease: a systematic review. Respir Care 2013. DOI:10.4187/respcare.02742. (In Press) 


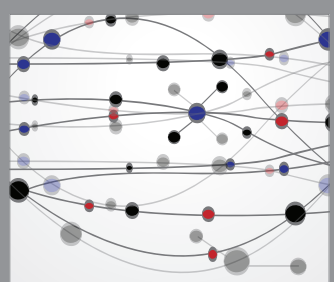

The Scientific World Journal
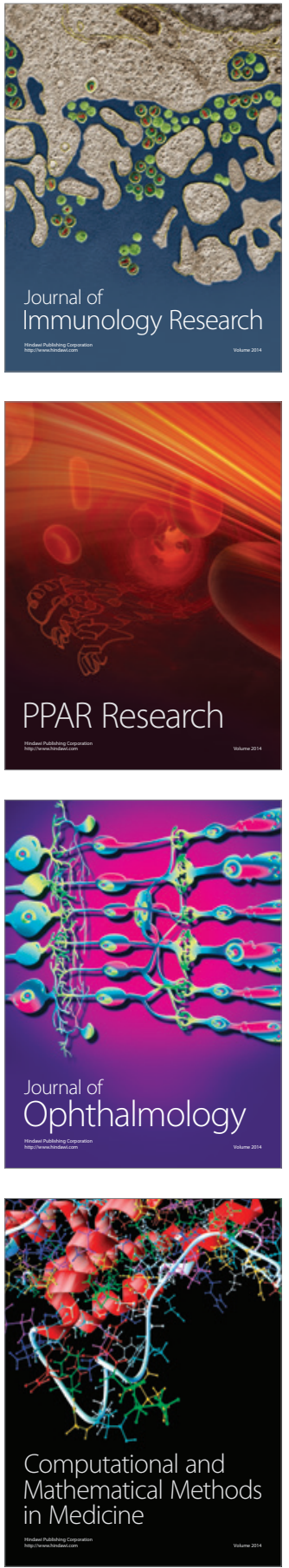

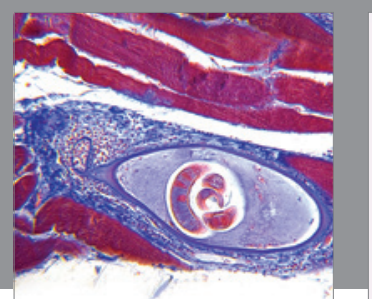

Gastroenterology Research and Practice

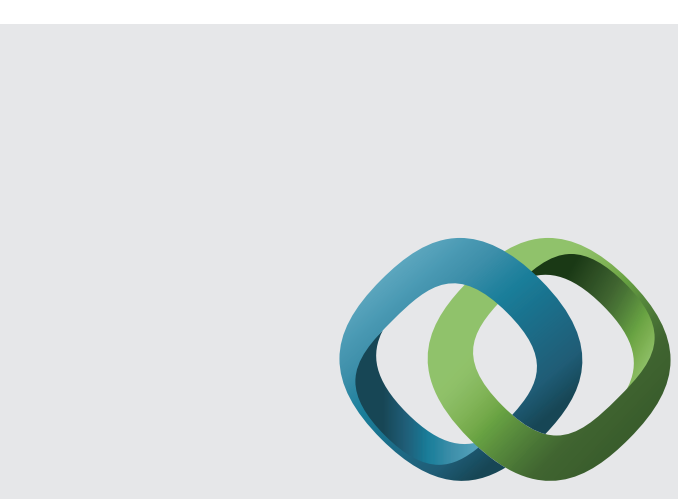

\section{Hindawi}

Submit your manuscripts at

http://www.hindawi.com
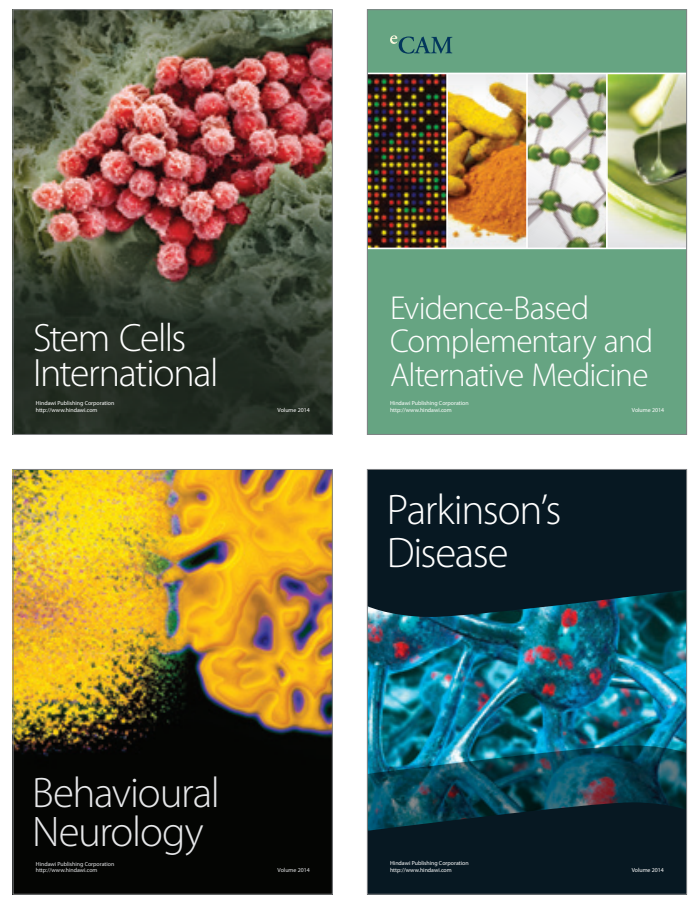
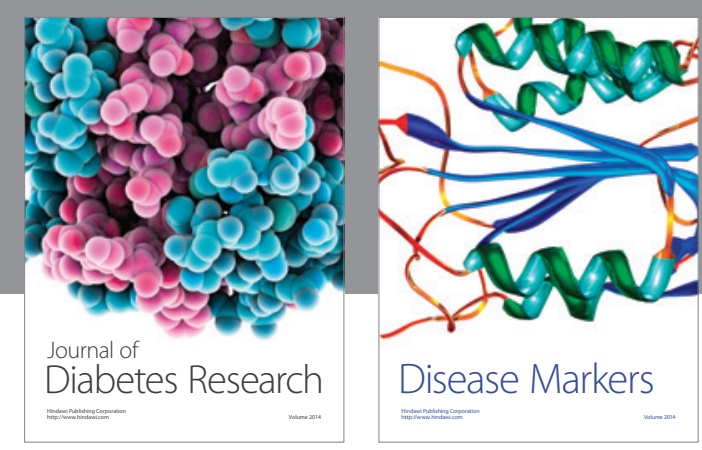

Disease Markers
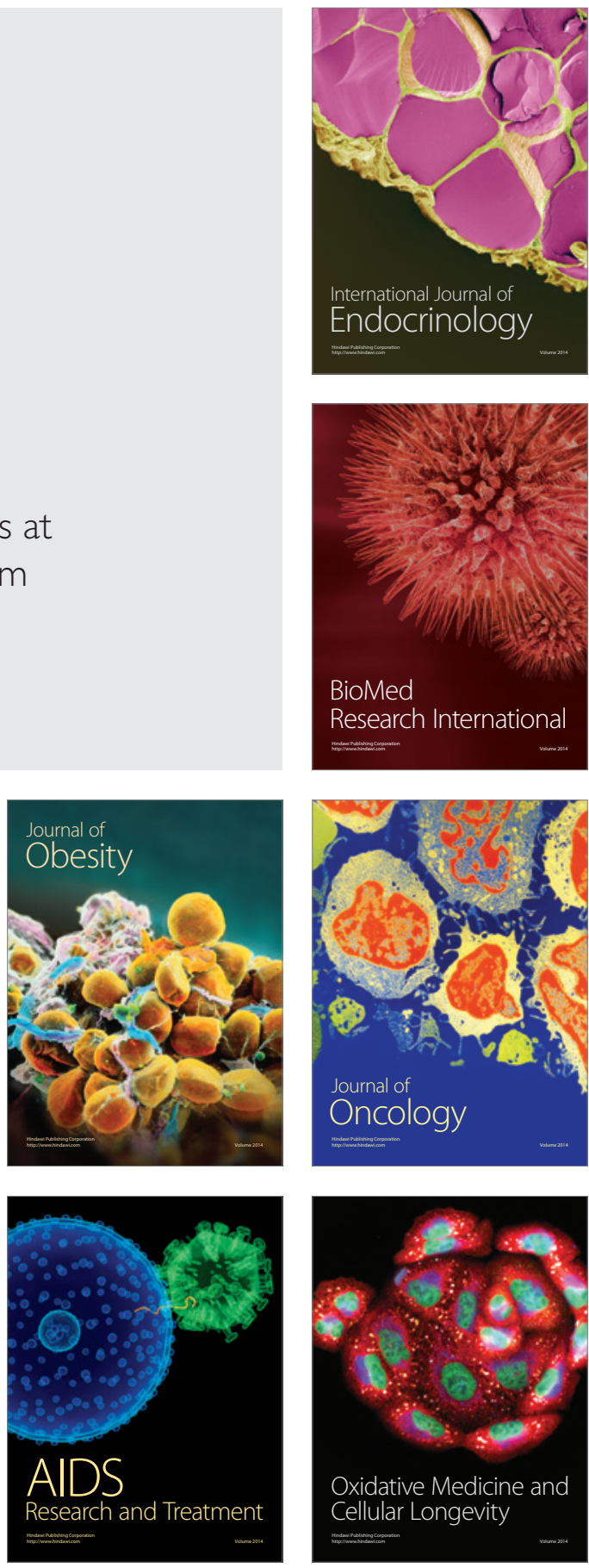